\title{
ANALYSIS OF VOLTAGE STABILIZERS AND NON-CONTACT RELAYS IN POWER SUPPLY SYSTEMS
}

\author{
Raxmatillo Karimov ${ }^{1 *}$, Maxsud Bobojanov ${ }^{1}$ \\ ${ }^{1}$ Tashkent state technical university named after Islam Karimov, 100095, Uzbekistan, Tashkent, University St. 2A
}

\begin{abstract}
The article discusses the results of comparison and analysis of voltage stabilizing devices and contactless relays in the power supply system. Based on the analysis, the time variation of the voltage in the capacitive circuit is shown. Based on the results of the study, it was found that the determination of the actual value of the capacitive voltage by controlling the thyristor of the "charge-discharge" process of the capacitance makes it possible to determine the time delay of the contactless switching device when the capacitor reaches the saturation point.
\end{abstract}

\section{Introduction}

In Uzbekistan, indicators of the quality of electricity in the power supply system are characterized by eleven indicators approved by the State Standard of Uzbekistan O'zDSt 1044:2003 and the Interstate Standard GOST 32144-2013 [1, 2].

Power quality needs to be seen as related to two views $[1,3]$ :

- electricity as a commodity, the quality of which must correspond to very specific market requirements;

- electricity capable of performing work in the process of its production, transmission, distribution and consumption.

According to the requirements of a market economy, when providing consumers with high-quality electricity, there are legal norms and requirements for all participants involved from electricity production to its consumption $[2,3,4]$.

At present, power contactless semiconductor equipment has become intensively used, which has significantly expanded the field of application of semiconductor technology in a number of areas of electrical engineering and provided qualitatively new results. Achievements in power semiconductor electronics have made it possible to master a new class of electrical devices - contactless semiconductor equipment $[1,2,5]$.

At the same time, non-contact semiconductor devices allow solving the problem of fast current limitation, limiting emergency currents, reducing the effects of short-circuit currents on the elements of power supply systems, simplifying the connection of electrical receivers with a rapidly alternating shock load, ensuring self-starting of large electrical machines, controlling the reactive elements of the network - reactors, capacitor banks and improving the quality electricity in distribution networks $[3,4,5]$.

\section{Requirements for the quality of electricity in industrial processes}

Each electrical receiver for normal operation requires certain indicators of network parameters, such as: rated frequency, voltage, etc., i.e. high-quality electrical energy $[1,2,3]$.

The reason for the deterioration in the quality of electricity generated by power plants may be the poor technical condition of the lines and transformer substations, as well as the remoteness of consumers from the power source $[1,3,5]$.

The quality of electricity is assessed according to technical and economic indicators that take into account the damage from low-quality electricity $[1,5,6]$ :

- technological damage - damage in the power supply systems of consumers associated with rejects and undersupply of products;

- electromagnetic damage - damage in the electric power industry from increased losses of electricity and disruption of electrical equipment.

The reliability of electricity supply depends on the quality of electricity when consumers are provided with the required amount of electricity and continuity [2, 4].

The operation of the power system can be characterized by four modes $[1,2,7]$ :

- normal mode, when the power quality indicators deviate from their nominal values and do not go beyond their permissible limits for a long time;

- temporarily permissible modes when current overloads, voltage changes, etc. are observed, which are provided for in the project documentation or are allowed for a short time without damage to the network;

- emergency modes arising from damage to network elements, which are unstable;

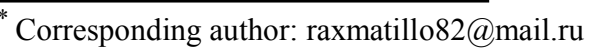


- post-emergency modes, characterized by both transient processes that occur when power is restored, and steady-state modes under new power conditions.

For all of the above types of electrical system operation modes, the power quality indicators or their permissible values for magnitude and duration are standardized separately [7].

This paper examines two of the main indicators of power quality: voltage deviation and fluctuations; harmonic component of voltage.

\section{Research and analysis of the work of stabilizing devices}

In power supply systems, special technical means of regulation are used as stabilizing devices to improve the quality of voltage at consumers. Common reasons that lead to the failure or failure of electrical equipment and the failure of the technological process are voltage surges directly at the consumer. Any manufacturer of electrical equipment designs on the assumption that all electrical equipment and devices must be designed to operate on a network that meets the requirements of the standard $[1,2,8]$.

A change in the magnitude or shape of a voltage is commonly referred to as voltage distortion. These distortions impair the performance of electrical appliances, up to and including their failure. Therefore, the question arises of protecting electrical appliances from voltage changes $[5,6]$.

To avoid undesirable effects of voltage changes, as a rule, an apparatus (voltage stabilizer) is used, which automatically regulates a given voltage in the electrical network $[7,8]$.

In some cases, in power supply systems, the power quality does not meet the requirements of O'zDSt 1044: 2003. Deviation from the nominal value, abrupt change, oscillation, high-frequency obstruction, high-voltage impulses lead to a low indicator of power quality $[1,2]$.

Household electrical consumers used in everyday life are very sensitive to the quality of electricity. Of these, a computer, audio equipment, TV, refrigerator and washing machine remain at risk from poor quality electricity. In such cases, before buying household electrical appliances, it becomes necessary to purchase voltage stabilizers. The stabilizers offered by most enterprises have their own advantages and disadvantages $[1,2,9,10]$.

Voltage stabilizers, in addition to protecting household consumers, also provide high-quality electricity to city and district-settlement consumers.

Currently, there are mainly four groups of voltage stabilizers on the market that are divided according to the principles of operation:

- electromagnetic;

- electromechanical;

- step relay;

- step electronic.

Each of these groups have their own positive and negative properties.
Electromagnetic voltage stabilizers. In such stabilizers, voltage stabilization occurs due to a change in the magnetic flux in the transformer core. Flux changes are made by changing the magnetic permeability of the core gap, for this, special cores with a gap are used, or using additional windings controlled by semiconductor circuits. In stabilizers, where cores with a gap are used, the total magnetic permeability of the circuit changes and, accordingly, the total flux of the core. In stabilizers with additional windings, a change in the magnetic flux created by these windings leads to a change in the total flux in the core $[4,6,8]$.

Circuits with semiconductor elements are used as control elements in these stabilizers, the speed of which characterizes the speed of the electromagnetic voltage stabilizer as a whole $[2,9,10]$.

The main advantages of this type of stabilizers are:

- smooth voltage regulation;

- relatively high stabilization accuracy;

- high speed of work;

- idle work;

- filtering the voltage at the input and output of the stabilizer;

- wide temperature range of work;

- lack of mechanical movements.

The disadvantages include:

- small stabilization range;

- limited overload capacity;

- the power of the stabilizer depends on the maximum power of the load;

- the presence of noise during the operation of the stabilizer.

Electromechanical voltage stabilizers with a booster transformer operate by regulating an autotransformer mounted on the servo drive shaft $[4,6,8]$.

Advantages of this type of stabilizer:

- smooth voltage regulation;

- high stabilization accuracy;

- high overload capacity;

- the form of the stabilized voltage is sinusoidal;

- works with no load;

- the voltage stabilizer is silent during operation;

- the voltage stabilizer is silent during operation.

The disadvantages include:

- the presence of wear on the brush and servo;

- relatively complex service;

- at subzero temperatures, a heating system is required.

Step relay voltage stabilizers stabilize the voltage by regulating the inclusion of the number of transformer windings. The regulation of the number of windings is carried out using electromechanical relays $[4,6,8]$.

Dignity:

- high stabilization accuracy;

- the consumption of non-ferrous metal per kilowatt of stabilized power is not great;

- the stabilizer operates at zero load;

- phases are stabilized independently;

- the stabilizer works almost silently;

- the stabilizer is insensitive to changes in the mains frequency;

- the voltage waveform is almost sinusoidal; 
- relatively wide operating temperature range.

Disadvantages:

- has a low overload capacity;

- relatively low performance;

- low reliability of the stabilizer;

- the presence of wear on the mechanical parts of the relay.

Electronic step voltage stabilizers with a booster transformer stabilize the voltage in the same way as step relay stabilizers by regulating the inclusion of the number of transformer windings. The regulation of the number of windings occurs using semiconductor circuits $[4,6,8]$.

The merits include:

- wide temperature range of work;

- there are no mechanically working contacts in the design;

- the consumption of non-ferrous metal per kilowatt of power is not great;

- the stabilizer operates at zero load;

- silent;

- insensitive to changes in network frequency.

The disadvantages of the stabilizer include:

- low overload capacity;

- the speed of the stabilizer depends on the number of steps in the additive stage;

- the shape of the output voltage is significantly different from the sinusoid;

- low reliability due to the large number of electronic keys.

\section{Analysis of control circuits of voltage stabilizers}

The most common stabilizers at the present time are voltage stabilizers with step regulation, the power blocks of which are built on the basis of transformer-key structures $[6,8,11]$.

The advantages of this type of voltage stabilizers include:

- the speed of their work;

- large variation in input voltage;

- the ability to work at idle;

- sinusoidal shape of the output voltage;

- high efficiency.

The disadvantages include:

- limiting the accuracy of stabilization, due to a step change in the output voltage.

As shown by the analysis of the classification of transformer-key structures (Fig.1), structures with keys located in the power current circuit should be calculated for the full load power. Structures with keys removed from the power current circuits and not galvanically connected to the supply network and to the load allow the use of thyristors with a low rated current for switching and provide a greater number of operating modes with an equal number of keys with other circuits, and structures where some of the keys are located in power current circuits, and the other part is removed from it, are used in voltage stabilizers with an intermediate link of increased frequency, moreover, in them, the voltage boost voltage transformation occurs at an increased frequency $[6,8,9]$.

Currently, in medium and high-power $\mathrm{AC}$ voltage power regulators, implemented on the basis of transformer-key structures, thyristors (controlled semiconductor elements with one-way conductivity) are used to implement the key control method. The thyristor switch contains two counter-parallel connected thyristors, each of which is designed to apply not only forward, but also full reverse voltage acting in the circuit $[6,8,9]$.

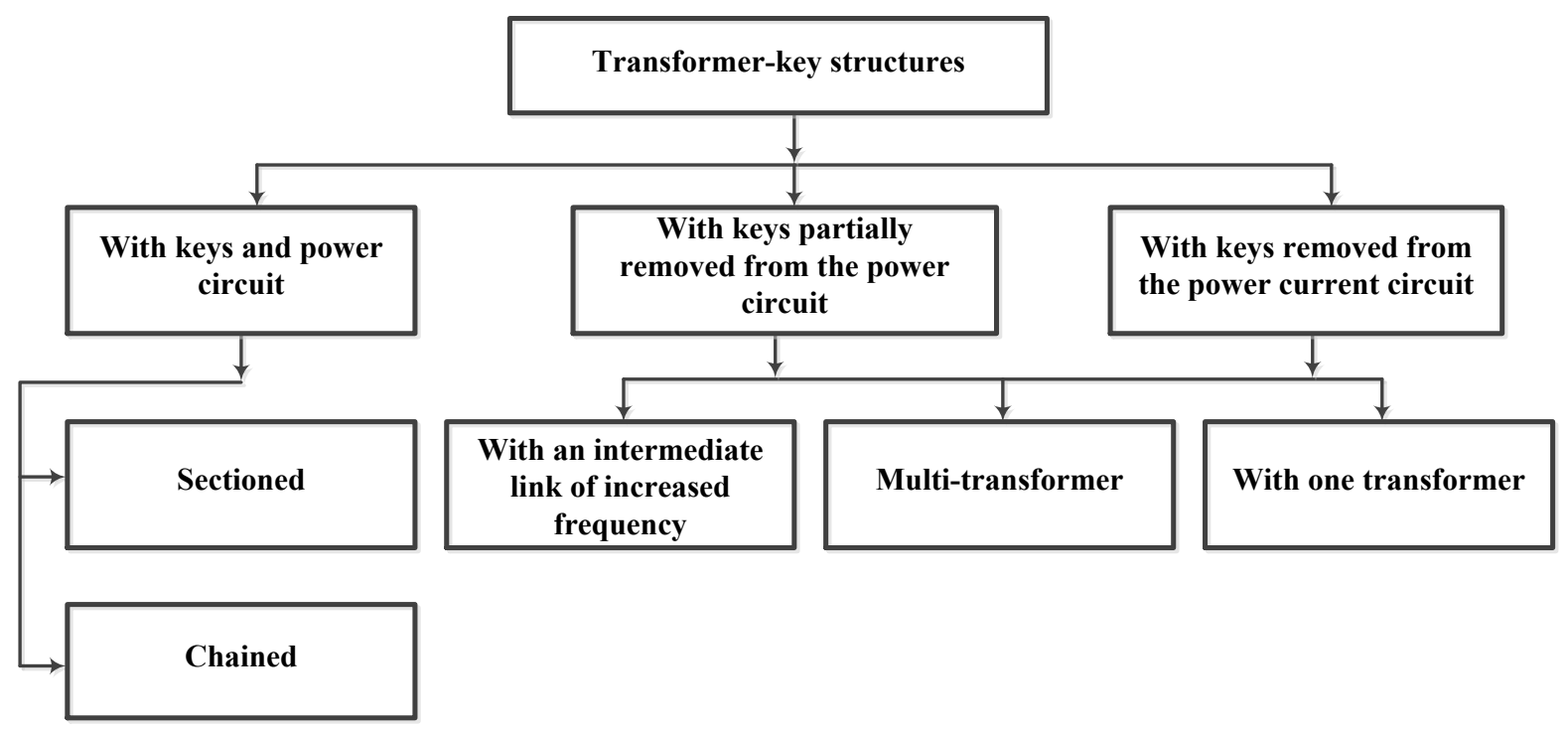

Fig.1. Classification of transformer-key structures 
There are two types of thyristor-based AC power stabilizers: with smooth and step voltage regulation (see Fig.2).

With smooth regulation, the voltage is stabilized by changing the angle of the thyristors $[8,9]$.

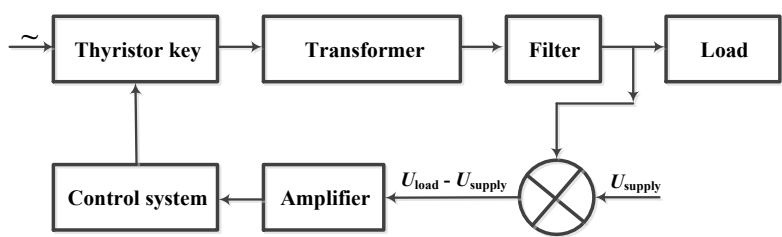

Fig.2. Functional diagram of a voltage regulator with a thyristor switch

Step stabilization is carried out by switching the taps of the power transformer with thyristor switches. These stabilizers, called transformer-thyristor, are based on the circuit design shown in Figure 3.

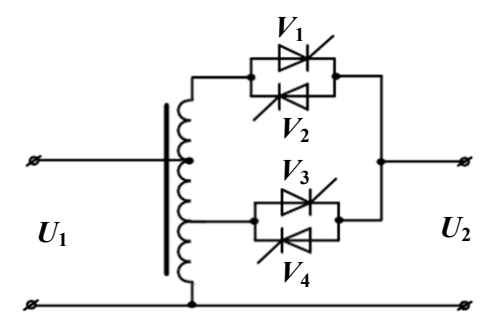

Fig.3. Electrical circuit of the transformer-thyristor voltage stabilizer

In this case, the load is connected through the thyristors to the autotransformer windings, and the voltage is stabilized by changing the transformation ratio with the help of thyristors [11].

An analysis of the features of voltage stabilizers with thyristor switches showed that on this principle two types of stabilizers can be created: by floating regulation and step voltage regulation. In the first types of stabilizers, certain requirements are imposed on thyristor control pulses, since with asymmetric control pulses, a forced magnetization current appears in the primary winding of the power transformer, which contributes to an increase in starting currents, a decrease in efficiency and power factor $[10,11]$.

In addition, in voltage stabilizers with smooth regulation, it is necessary to take measures for automatic correction of the thyristor switching angle, which complicates the control system of the entire device, increases their weight and dimensions [11, 12].

In voltage stabilizers of the second type, a transformer-thyristor regulator, which is an executive element of the stabilizer, is a link with a fixed delay due to the fact that open thyristors can close only when the direction of the current flowing through them changes. The magnitude of this delay can reach the duration of one half-cycle of the supply voltage. In this case, thyristors $B_{1}$ and $B_{4}$ or $B_{2}$ and $B_{3}$ will be simultaneously open (Fig.3), which will cause a short-circuit of the winding, flow of a short-circuit current and breakdown of thyristors. Such an abnormal mode is possible at low values of $\cos \varphi$ of the load, when the mains voltage and load current are significantly different in phase $[12,13]$.

Overvoltages, which arise both in emergency modes and in normal modes, pose a great danger to the operation of thyristors. This can be explained by the fact that there are chokes and capacitors in the circuits, in which energy fluctuations occur during the transition of the load current from one valve to another. Thus, transient processes constantly occur in the circuit, leading to a sharp change in energy, consequently to overvoltage on the thyristors.

In order to improve reliability, it is necessary to take special measures to ensure accurate commutation of controlled valves, which, naturally, complicates the control circuit $[13,14]$.

An analysis of the operation of semiconductor stabilizers using the discrete principle of voltage regulation showed that along with high efficiency, power factor, voltage stabilization factor, insignificant distortion of the output voltage, these stabilizers have an increased complexity of the control system and insufficient reliability of controlled valve switches [15].

In the considered voltage regulators with key structures, solid-state relays are often used. Which are increasingly taking place in modern technological areas such as communication systems, consumer electronics and industrial automation, i.e. there is an intense transition from conventional switching schemes using conventional electromagnetic relays and moving contact starters to more reliable switching tools such as solidstate semiconductor relays $[14,16]$.

Solid state relays can consist of powerful semiconductor elements that replace the contacts of electromagnetic devices (relays, starters and contactors). Solid state relays currently available can switch load currents up to $250 \mathrm{~A}$. Moreover, in such relays there is no need for galvanic isolation of the control circuit from its power section $[8,13,14,16]$.

Solid state relays have the following structure:

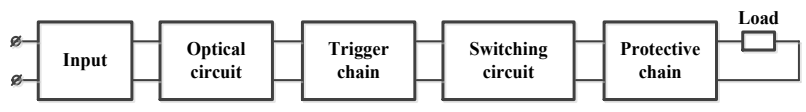

Fig.4. Solid state relay structure diagram

The input voltage is applied to the input circuit of the relay, which performs the function of receiving the control signal and transmitting it to the optical isolation circuit, which provides isolation between the input, intermediate and output circuits. The input signal is transmitted to the trigger circuit for processing and creating a signal to control the switching of the relay output (Fig.5) [8, 14, 17].

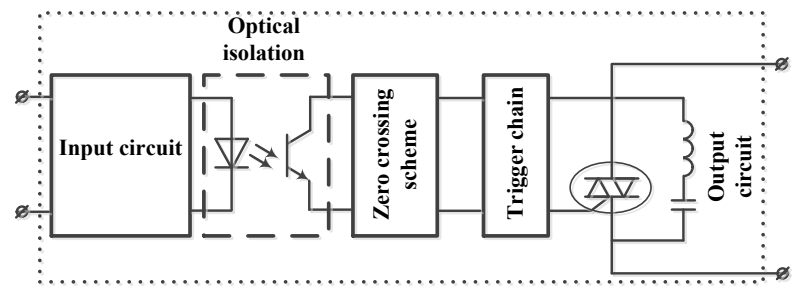

Fig.5. Schematic diagram of a solid state relay 
The switching circuit that transfers voltage to the load consists of a transistor, thyristor or triac. The disadvantage of solid state relays is the complexity of the circuit $[14,16,18]$.

The switching circuit has a switching relay with transformer decoupling, two switches on a transistor, a pulse generator, a pulse transformer, two diodes, a current setting resistor, a Zener diode, current limiting and discharge resistors $[16,17,18]$.

Currently, electronic switching relays with transformer decoupling of input and output have been developed (Fig.6), where the transformer is made in the form of a pulse transformer, and the switching device is made on the basis of a transistor $[11,13,14]$.

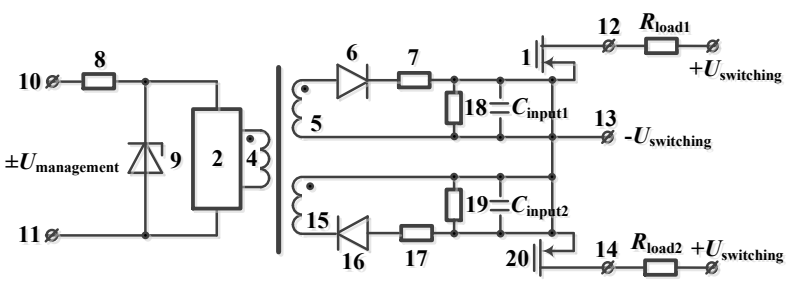

Fig.6. Schematic diagram of a transformer decoupled electronic switching relay

These relays have the following disadvantages:

- limiting the current of the switched circuit;

- the complexity of the circuit;

- impossibility of developing control systems using integral elements.

The currently produced optoelectronic relays (Fig. 7) have an LED and four optically connected photocells connected in series, a switching device, a resistor acting as a discharge device, to the terminals of which they are connected to the positive and negative outputs of seriesconnected photodiodes. Also, the input of the switching device is connected to these terminals, i.e. the gate and source of the transistor. Thus, for this relay, the outputs are the drain and source of the transistor, and the inputs are the anode and cathode of the LED $[13,14,18]$.

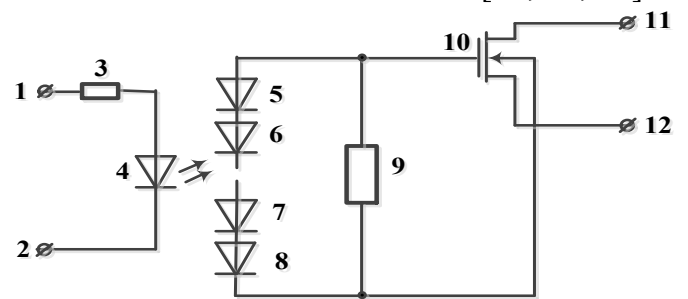

Fig.7. Schematic diagram of an optoelectronic relay

The disadvantage of this relay can be attributed to their low switching power.

An optoelectronic relay is also known, containing, in addition to the listed elements of the above relay: a switching device, a discharge device, a discharge accelerator device used to improve the dynamic characteristics of the relay (Fig.8) [13, 14].

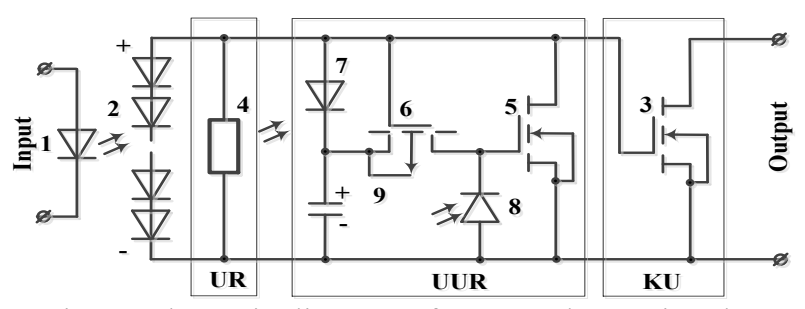

Fig.8. Schematic diagram of an optoelectronic relay

The disadvantages of this relay is the absence of a load current limiting device.

This optoelectronic relay (Fig.9) is used in switching devices with galvanic isolation. This relay has, in addition to the elements of the above relay, a capacity that creates a delay in the operation of the first transistor $[14,16,18]$.

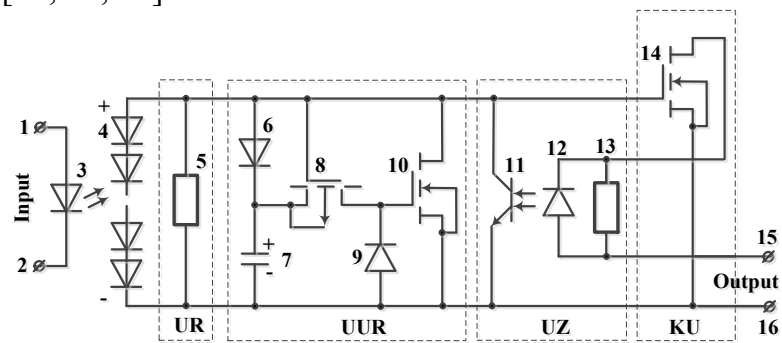

Fig.9. Schematic diagram of an optoelectronic relay

This relay has the same disadvantages as the relay shown in Fig.9.

\subsection{Optoelectronic proximity voltage relay}

The shape of the load current can be influenced by controlling the firing angle of the thyristor. When the phase shift $\varphi$ between the load current and the control signal is equal to zero, the load current curve will have the form of a sinusoid [4, 7, 9, 20, 21].

Thus, in order to ensure sinusoidal, current and voltage waveforms across the load, it is necessary to send a signal to open the thyristor when the current passes through zero $[10,11]$.

Figure 10 shows a circuit diagram of a non-contact voltage relay with a sinusoidal voltage waveform across the load [19]. 


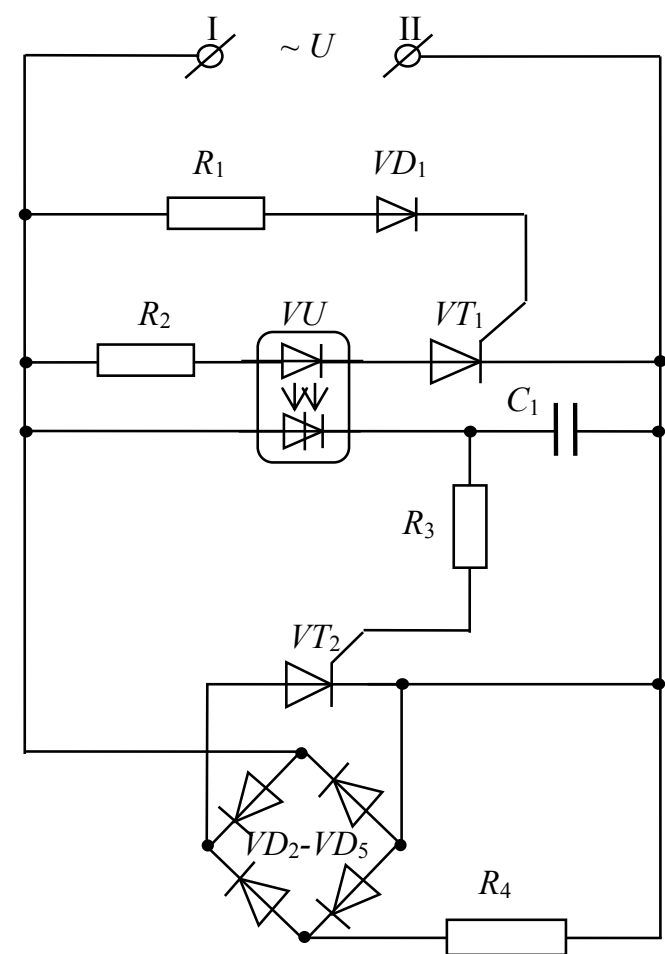

Fig.10. Schematic diagram of an optoelectronic proximity voltage relay

Consider the operation of an optoelectronic contactless voltage relay. One of the main advantages of electromagnetic relays (creation of galvanic isolation) is also characteristic of optocouplers. At the same time, optoelectronic devices have better performance than electromagnetic analogs in terms of reliability, durability and weight and size indicators $[13,15,18,19,22]$.

Optoelectronic relays, in comparison with electromagnetic installations, differ in reliability, durability and resistance to transient and frequency characteristics, improved technical and economic indicators and speed, makes it possible to use for switching transformer windings and relay protection installations without special devices $[13,19,23]$. The implementation of a contactless voltage relay using a thyristor and an optocoupler improves the weight and dimensions.

The non-contact voltage relay consists of a diode bridge $V D_{2}-V D_{5}$ connected to the power source in series with the load $R_{\text {load, }}$, the $V D_{2}-V D_{5}$ diode bridge in the diagonal of which the thyristor $V T_{2}$ is switched on. The relay is also equipped with a capacitor $C$, a thyristor $V T_{1}$, three active resistances $R_{1}, R_{2}, R_{3}$, a thyristor optocoupler $V U$ and a diode $V D_{1}$. The control electrode of the first thyristor $V T_{2}$ through the resistor $R_{3}$ is connected to the plate of the capacitor $C$ and the cathode of the thyristor of the optocoupler $V U$. The second plate of the capacitor $C$ is connected to the cathodes of the thyristor $V T_{2}$, the cathode of the second thyristor $V T_{1}$ and the second terminal of the supply network. The anode of the thyristor $V T_{1}$ is connected to the cathode of the diode of the $V U$ optocoupler, the anode of which is connected to the terminal of the resistor $R_{2}$. The second terminal of the resistor $R_{2}$ is connected to the anode of the thyristor of the optocoupler $V U$ and the first terminal of the resistor $R_{1}$ is also connected to the first terminal of the supply network. The second terminal of the resistor $R_{1}$ is connected to the anode of the diode $V D_{1}$, the cathode of which is connected to the control electrode of the thyristor $V T_{1}[13,19,24,25]$.

Consider the operation of an optoelectronic proximity voltage relay. When the unlocking signal on the control electrode reaches a value sufficient to unlock the thyristor, the thyristor $V T_{1}$ opens with an opening angle of $90^{\circ}$ and connects the diode of the optocoupler $V U$ to the network through a resistor. This leads to the opening of the thyristor of the optocoupler $V U$ and the flow of current through the diode of the optocoupler, thereby leading to the opening of the thyristor of the optocoupler $V U$, and turns on the capacitor $C$. Since a constant signal is supplied from the capacitor $C$ through the resistor $R_{3}$ to the control electrode of the thyristor $V T_{2}$, it remains open, and a sinusoidal current will flow through the load $R_{4}$. The operation of the thyristors $V T_{1}$ is regulated by changing the parameter of the resistor $R_{1}$ $[13,19]$.

This non-contact voltage relay has been tested in the laboratory of the "Power Supply" Department of the Power Engineering Faculty of the Tashkent State Technical University named after Islam Karimov. In this case, thyristors of the type KU202I, KU201I are used as thyristors $V T_{1}, V T_{2}$, respectively, thyristors of the type $K U 202 I$, KU201I, as a diode $V D_{1}-D 226 B$, as active resistances $R_{1}, R_{2}, R_{3}, R_{4}$, respectively, resistors of 820 Ohm, $15 \mathrm{kOhm}, 3.8 \mathrm{kOhm}, 16 \mathrm{kOhm}$, as a capacitance $C$ - a capacitor with a capacity of $1 \mu \mathrm{F}$, as an optocoupler used thyristor optocoupler $A O U 103 \mathrm{~V}$, diode bridge $V D_{2}-$ $V D_{5}-K T s 402 E$. Experimental studies have shown that the load $R_{4}$ was connected to the network at a voltage of $18 \mathrm{~V}$. The voltage waveform across the load is sinusoidal $[13,19]$.

Fig. 11-12 shows the appearance of an opto-thyristor proximity voltage relay and its input-output voltage characteristic.

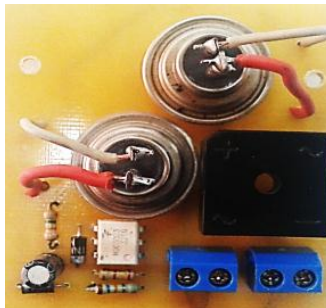

Fig.11. Appearance of the optoelectronic proximity voltage relay 


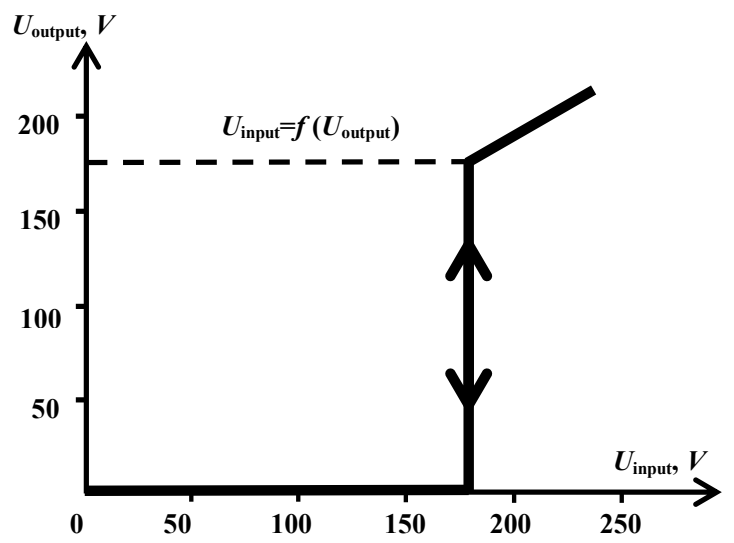

Fig.12. Voltage characteristic "input-output" thyristor relay voltage

\section{Conclusion}

1. Analysis of power quality indicators shows that it is necessary to use voltage stabilizers with a simple control circuit.

2. The study of the circuits of stabilizing devices showed that the voltage stabilizers offered by most enterprises have a complex design with a large number of elements, and this leads to a limitation of their field of application.

3 . The analysis of the given voltage stabilizers shows that thyristors or triacs are used as control elements, which leads to a significant distortion of the waveform at the output of the voltage stabilizer.

4. An analysis of the stabilization process shows that to regulate the operation of the stabilizer, it is necessary to use a system in the control circuit to open the thyristors at the moment the load current crosses zero.

5. Analysis of the study shows that the load $R_{\text {load }}$ is connected to the network at a voltage of $220 \mathrm{~V}$. Based on the above circuit, the developed voltage relay provides a sinusoidal voltage waveform across the load, while the return coefficient is close to unity.

\section{References}

1. State standard of Uzbekistan O'z DSt 1044:2003. Protocol 05-19 dated July 18, 2003. - PP.27.

2. State standard of Uzbekistan O'z DSt 1050:2004. Protocol 05-02 dated January 30, 2004. - PP.53.

3. Usmanov E.G., Abduraimov E.Kh., Karimov R.Ch. Bulletin TSTU, Tashkent, 3-4, - C.48-51, (2012).

4. Karimov R.Ch., Shamsiyev K., and others. IOP Conf. Series: Materials Science and Engineering, 883(1), 012142, (2020). doi:10.1088/1757-899X/883/1/012142

5. Karimov R.Ch., Shamsiyeva N. and others. IOP Conf. Series: Materials Science and Engineering, 883(1), 012120, (2020). doi:10.1088/1757-899X/883/1/012120

6. Milovzorov V.P., Musolin A.K. Uchebnoe posobie, M.: Izd. Energoatomizdat, - S.247, (1986).

7. E.G.Usmanov, A.N.Rasulov, M.K.Bobojanov, R.Ch.Karimov. E3S Web of Conferences 139, 01079 (2019), doi.org/10.1051/e3sconf/201913901079
8. Poskrobko A.A., Bratolyubov V.B. Uchebnoe posobie, - M.: Izd. Energiya, - S.192, (1978).

9. Karimov R.Ch. Technical science and innovation, 2, (2019). uzjournals.edu.uz/btstu/vol2019/iss2/8

10. Bobojanov M.K., Usmanov E.G., Abduraimov E.H., Karimov R.Ch. European Science Review, 1-2. PP.210-212, (2018).

11. Karimov R.Ch. European Science review, 9-10, PP.144-146, (2015).

12. G.Rafikova, M.R.Ruzinazarov, S.Makhmutkhonov. E3S Web of Conferences, 139, 01075, (2019), https://doi.org/10.1051/e3sconf/201913901075

13. Hoshimov, F.A., Bakhadirov, I.I., Erejepov, M., Djumamuratov, B. (2019) Development of method for normalizing electricity consumption E3S Web Conf 139 doi:10.1051/e3sconf/201913901074

14. Sulliev A.X., Karimov R.Ch. Bulletin Tashkent Institute of Railway Engineers, Tashkent, 4. - PP.149154, (2018).

15. Abduraimov E.Kh., Karimov R.Ch., Ruzinazarov M.R. Certificate of official registration of the computer program DGU 05850, (2018).

16. Bobojanov M.K., Rasulov A.N., Karimov R.Ch., Sattarov H.A. Bulletin Descendants of Mohammed AlKhwarizmi (ISSN: 2181-9211), Tashkent, 3(5), PP.106-109, (2018).

17. Rasulov A.N., Karimov R.Ch. European Science review, 9-10, - PP.140-143, (2015).

18. Rasulov A.N., Karimov R.Ch. EESJ, 4, - PP.174178, (2015), doi:10.12851/EESJ201508C05ART02

19. Usmanov E.G., Abduraimov E.Kh., Karimov R.Ch. Patent for invention of the Republic of Uzbekistan, IAP 05122, (2015).

20. A.D.Taslimov, I.U.Rakhmonov. Journal of Physics: Conference Series, 1399, 055046, (2019). doi:10.1088/1742-6596/1399/5/055046

21. I.U.Rakhmonov, L.Nematov, N.Niyozov, K.Reymov, T.M.Yuldoshev. Journal of Physics: Conference Series 1515, 022054, (2020). doi:10.1088/17426596/1515/2/022054

22. Karimov R.Ch., Bobojanov M.K., Rasulov A.N., Usmanov E.G. E3S Web of Conferences, 139, 01039, (2019), doi.org/10.1051/e3sconf/201913901039

23. I.U.Rakhmonov, K.M.Reymov, S.H.Dustova. IOP Conf. Series: Materials Science and Engineering 862, 062070, (2020). doi:10.1088/1757-899X/862/6/062070

24. Rasulov A.N., Karimov R.Ch. EESJ, 4, - PP.179183, (2015). doi:10.12851/EESJ201508C05ART01

25. Rismuhamedov D., Tuychiev F. and others. IOP Conf. Series: Materials Science and Engineering, 883(1), 012140, (2020). doi:10.1088/1757-899X/883/1/012140 